\title{
Hygro-responsive membranes for effective oil-water separation
}

\author{
Arun K. Kota ${ }^{1, \star}$, Gibum Kwon ${ }^{1, \star}$, Wonjae Choi ${ }^{2}$, Joseph M. Mabry ${ }^{3}$ \& Anish Tuteja ${ }^{1,4}$
}

There is a critical need for new energy-efficient solutions to separate oil-water mixtures, especially those stabilized by surfactants. Traditional membrane-based separation technologies are energy-intensive and limited, either by fouling or by the inability of a single membrane to separate all types of oil-water mixtures. Here we report membranes with hygro-responsive surfaces, which are both superhydrophilic and superoleophobic, in air and under water. Our membranes can separate, for the first time, a range of different oil-water mixtures in a singleunit operation, with $>99.9 \%$ separation efficiency, by using the difference in capillary forces acting on the two phases. Our separation methodology is solely gravity-driven and consequently is expected to be highly energy-efficient. We anticipate that our separation methodology will have numerous applications, including the clean-up of oil spills, wastewater treatment, fuel purification and the separation of commercially relevant emulsions.

\footnotetext{
${ }^{1}$ Department of Materials Science and Engineering, University of Michigan, Ann Arbor, Michigan 48109, USA. ${ }^{2}$ Department of Mechanical Engineering, University of Texas, Dallas, Richardson, Texas 75080, USA. ${ }^{3}$ Rocket Propulsion Division, Air Force Research Laboratory, Edwards Air Force Base, California 93524, USA. ${ }^{4}$ Macromolecular Science and Engineering, University of Michigan, Ann Arbor, Michigan 48109, USA. *These authors contributed equally to this work. Correspondence and requests for materials should be addressed to A.T. (email: atuteja@umich.edu).
} 
$\mathrm{R}$ ecent events including the Deepwater Horizon oil spill in the Gulf of Mexico have highlighted the difficulty of effective oil-water separation. Efficient, cost-effective processes for oil-water separation, especially in the presence of dispersants (or surfactants), are greatly desired ${ }^{1}$. Surfactant-stabilized mixtures of oil and water are classified ${ }^{2}$, in terms of the diameter $(d)$ of the dispersed phase, as free oil and water if $d>150 \mu \mathrm{m}$, a dispersion if $20 \mu \mathrm{m} \leq d \leq 150 \mu \mathrm{m}$, or an emulsion if $d<20 \mu \mathrm{m}$. Conventional gravity separators and skimming techniques are incapable of separating emulsions ${ }^{2}$. Membrane-based technologies are attractive for demulsification (the conversion of an emulsion to a free oil-water mixture) because they are relatively energy-efficient, cost-effective, and are applicable across a wide range of industrial effluents ${ }^{2}$. However, for complete oil-water separation, demulsification is typically followed by either gravity separation or skimming.

Membranes are typically classified as either hydrophobic or hydrophilic ${ }^{3-10}$. Their wettability by oil is often not specified because, in most cases, such membranes are oleophilic, that is, their contact angle with oil is $<90^{\circ}$. Hydrophobic (or superhydrophobic $^{9-11}$ ) and oleophilic membranes are typically used in energyintensive cross-flow filtration systems ${ }^{3,6,7}$ because they are unsuitable for gravity-driven oil-water separation. This is because water naturally settles below oil and against the membrane owing to its higher density, forming a barrier layer that prevents oil permeation. Hydrophobic and oleophilic membranes are also easily fouled by oil during demulsification ${ }^{6,7}$. Although conventional hydrophilic membranes can be used for gravity-driven demulsification, and are more resistant to fouling ${ }^{2}$, they are unsuitable for the separation of free oil-water mixtures or water-in-oil emulsions because both oil and water can easily permeate through them (see Supplementary Fig. S1 and Supplementary Discussion).

As many as three different phases (oil, oil-in-water or water-inoil emulsion and water) may co-exist in oil-water mixtures ${ }^{12,13}$. To effect the gravity-driven separation of all types of oil-water mixtures in a single step, the ideal membrane is expected to be hydrophilic (or superhydrophilic ${ }^{14}$ ) and oleophobic (or superoleophobic ${ }^{15}$ ), both in air and when submerged in water. However, a membrane that is oleophobic in air typically loses its oleophobicity under water, and vice versa ${ }^{16,17}$

Most surfaces that are superoleophobic (displaying apparent contact angles for oil of $\theta^{*}{ }_{\text {oil }}>150^{\circ}$ ) are also superhydrophobic $^{15,18,19}$. This is due to the higher surface tension of water, which results in the respective Young's contact angles ${ }^{20}$ satisfying $\theta_{\text {water }}>\theta_{\text {oil }}$. A few studies ${ }^{14,21-26}$ have reported surfaces where $\theta_{\text {water }}<\theta_{\text {oil }}$, which was achieved by using specific interactions between water and the substrate to lower the solid-liquid interfacial tension $\left(\gamma_{\mathrm{sl}}\right)$. However, with two exceptions ${ }^{14,25}$ all such surfaces were oleophilic.

The systematic design of membranes for oil-water separation requires the parameterization of two important physical characteristics: surface porosity, which affects the rate of permeation of one phase (for example water) through the membrane, and breakthrough pressure $\left(P_{\text {breakthrough }}\right)$, the maximum pressure difference across the membrane below which the membrane prevents the permeation of the second phase (for example oil). Recent work $15,18,19,27-30$ has explained how 're-entrant surface texture', in conjunction with surface chemistry and roughness, can be used to design superoleophobic surfaces. We have previously discussed the spacing ratio, $D^{*}$, which is a dimensionless measure of surface porosity ${ }^{19}$. For substrates possessing a cylindrical texture, such as those considered here, $D^{*}=(R+D) / R$, where $R$ is the cylinder radius and $2 D$ is the intercylinder spacing. Higher values of $D^{*}$ indicate higher porosity and, therefore, a higher permeation rate for the contacting liquid. We also discussed the robustness factor ${ }^{19}, A^{*}$, which is the ratio of $P_{\text {breakthrough }}$ and a reference pressure, $P_{\text {ref }}=2 \gamma_{\mathrm{lv}} / l_{\text {cap }}$.
Here $l_{\text {cap }}=\sqrt{\gamma_{\mathrm{lv}} / \rho g}$ is the capillary length for the liquid, $\gamma_{\mathrm{lv}}$ is the liquid surface tension, $\rho$ is the liquid density and $g$ is the acceleration due to gravity. The reference pressure is approximately the minimum possible pressure that may be applied to a membrane by commonly occurring liquid droplets or puddles ${ }^{19}$. As a result, any membrane with $A^{\star} \leq 1$ for a given liquid cannot prevent liquid permeation, whereas values of $A^{\star} \gg 1$ imply a high resistance to liquid permeation. For surfaces possessing a cylindrical texture, the robustness factor is given by ${ }^{19,28}$

$$
A^{*}=\frac{P_{\text {breakthrough }}}{P_{\text {ref }}}=\frac{R l_{\text {cap }}}{D^{2}} \frac{1-\cos (\theta)}{1+2(R / D) \sin (\theta)} .
$$

Recently, we reported a gravity-assisted, electric field-driven methodology for separation of oil-water emulsions in a single-unit operation $^{31}$. However, that methodology requires continuous application of a very high voltage and is limited to separation of a few millilitres of emulsions. Guided by the design parameters discussed above, in this paper we develop novel membranes with hygroresponsive surfaces ${ }^{30}$, which are both superhydrophilic $\left(\theta^{*}{ }_{\text {water }} \approx 0^{\circ}\right)$ and superoleophobic $\left(\theta^{*}{ }_{\text {oil }}>150^{\circ}\right)$ both in air and under water. Our membranes can separate, for the first time, several litres of oil-water mixtures, including surfactant-stabilized emulsions, solely using gravity, in a single-unit operation, with $>99.9 \%$ separation efficiency, by using the difference in capillary forces acting on the two phases. Our separation methodology is solely gravity-driven and consequently is expected to be highly energy-efficient. We demonstrate the separation of several litres of oil-water mixtures using a scaled-up apparatus. We also demonstrate continuous separation of oil-water emulsions for over $100 \mathrm{~h}$ without a decrease in flux.

\section{Results}

Wetting behaviour of water and oil. Figure 1a,b show the wetting behaviour of water $\left(\gamma_{\mathrm{lv}}=72.1 \mathrm{mNm}^{-1}\right)$ and rapeseed oil $\left(\gamma_{\mathrm{lv}}=35.7 \mathrm{mN} \mathrm{m}^{-1}\right)$ on a stainless steel mesh 100 (Fig. 1a, inset; Methods) and polyester fabric (Fig. 1b, inset), each dip coated with a blend of $20 \mathrm{wt} \%$ fluorodecyl polyhedral oligomeric silsesquioxane (POSS) ${ }^{15}$ and cross-linked poly(ethylene glycol) diacrylate (x-PEGDA; Methods). For a surface spin coated with a $20 \mathrm{wt} \%$ fluorodecyl POSS + $\mathrm{x}$-PEGDA blend (solid surface energy $\gamma_{\mathrm{sv}}=10.5 \mathrm{mN} \mathrm{m}^{-1}$, see Supplementary Table S1), the advancing contact angle for rapeseed oil is $\theta_{\text {oil,adv }}=88^{\circ}$. This yields $A^{*}$ oil values of 8.6 and 4.3 for rapeseed oil on the mesh and fabric membranes, respectively. Because $D_{\text {fabric }}^{*}=6$ is greater than $D_{\text {mesh }}^{*}=2.2$, the observed apparent advancing contact angle on the dip-coated fabric $\left(\theta^{*}{ }_{\text {oil,adv }}=152^{\circ}\right)$ is higher than that on mesh $100\left(\theta^{*}{ }_{\text {oil, adv }}=125^{\circ}\right)$. However, despite their low surface energies, both the fabric and the mesh membranes are readily permeated by water, with $\theta^{*}$ water $=0^{\circ}$. This is a direct consequence of the surface reconfiguration induced by the contacting water droplet, as discussed below.

Figure 1c-e shows atomic force microscope (AFM) phase images of $x$-PEGDA and two fluorodecyl POSS + $x$-PEGDA blends in air. Although crystalline domains are absent on the neat $x$-PEGDA surface (Fig. 1c), the surfaces of both the $10 \mathrm{wt} \%$ (Fig. 1d) and the $20 \mathrm{wt} \%$ (Fig. 1e) blends are completely covered with crystalline domains of fluorodecyl POSS. This indicates substantial surface segregation of the fluorodecyl POSS molecules, as may be expected owing to their extremely low surface energies ${ }^{15}$. This surface migration leads to a rapid decrease in both the dispersive $\left(\gamma_{\mathrm{sv}}^{\mathrm{d}}\right)$ and the polar components $\left(\gamma_{\mathrm{SV}}^{\mathrm{p}}\right)$ of the blend surface energy (see Supplementary Fig. S2, Supplementary Table S1 and Supplementary Discussion).

Surface reconfiguration and time of wetting. Figure $2 \mathrm{a}, \mathrm{b}$ display optical images of spin-coated surfaces of $20 \mathrm{wt} \%$ fluorodecyl POSS + $x$-PEGDA, in air (Fig. 2a) and under water (Fig. 2b). In air, the surface is relatively rough, with several fluorodecyl POSS 

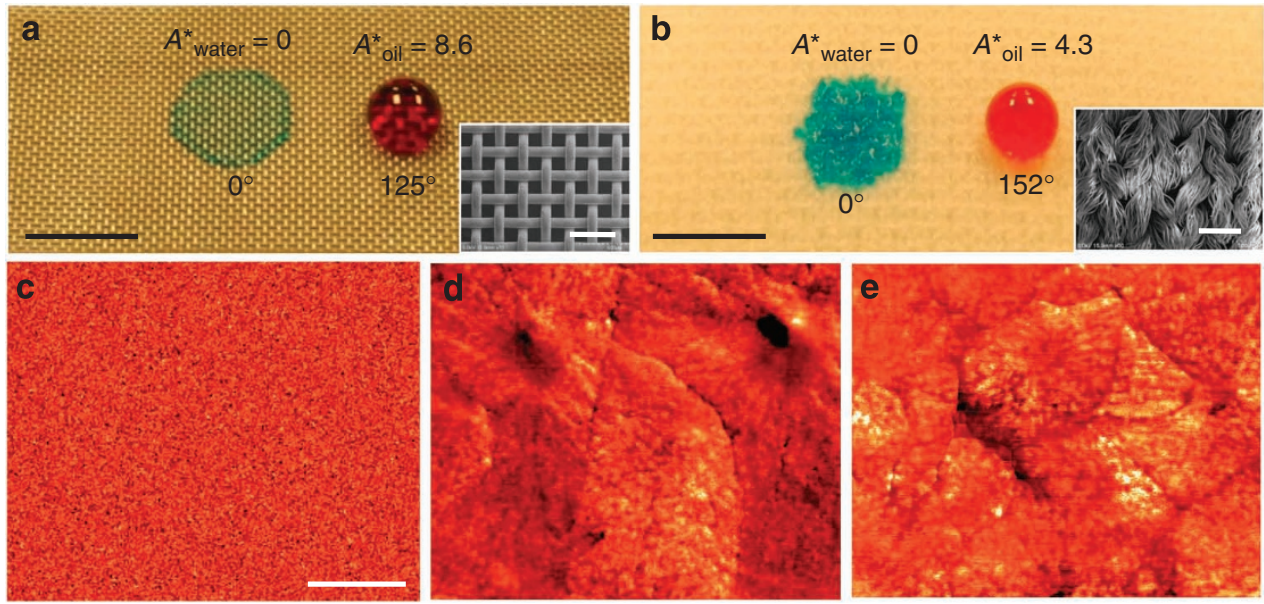

Figure 1 | Wetting behaviour of water and oil. (a,b), Droplets of water (dyed blue) and rapeseed oil (dyed red) on stainless steel mesh 100 (a) and polyester fabric (b). Both surfaces have been dip-coated with a 20 wt \% fluorodecyl POSS +x-PEGDA blend. Scale bars, $5 \mathrm{~mm}$. Insets, morphologies of the respective dip-coated mesh and fabric surfaces. Scale bars, $500 \mu \mathrm{m}$. (c-e) AFM phase images of surfaces coated with x-PEGDA (c), a 10 wt $\%$ fluorodecyl POSS $+x-$ PEGDA blend (d) and a 20 wt $\%$ fluorodecyl POSS $+x-$ PEGDA blend (e). The phase angle ranges are $0^{\circ}-115^{\circ}(\mathbf{c}), 0^{\circ}-25^{\circ}(\mathbf{d})$ and $0^{\circ}-21^{\circ}(\mathbf{e})$. Scale bar, $2 \mu \mathrm{m}$.
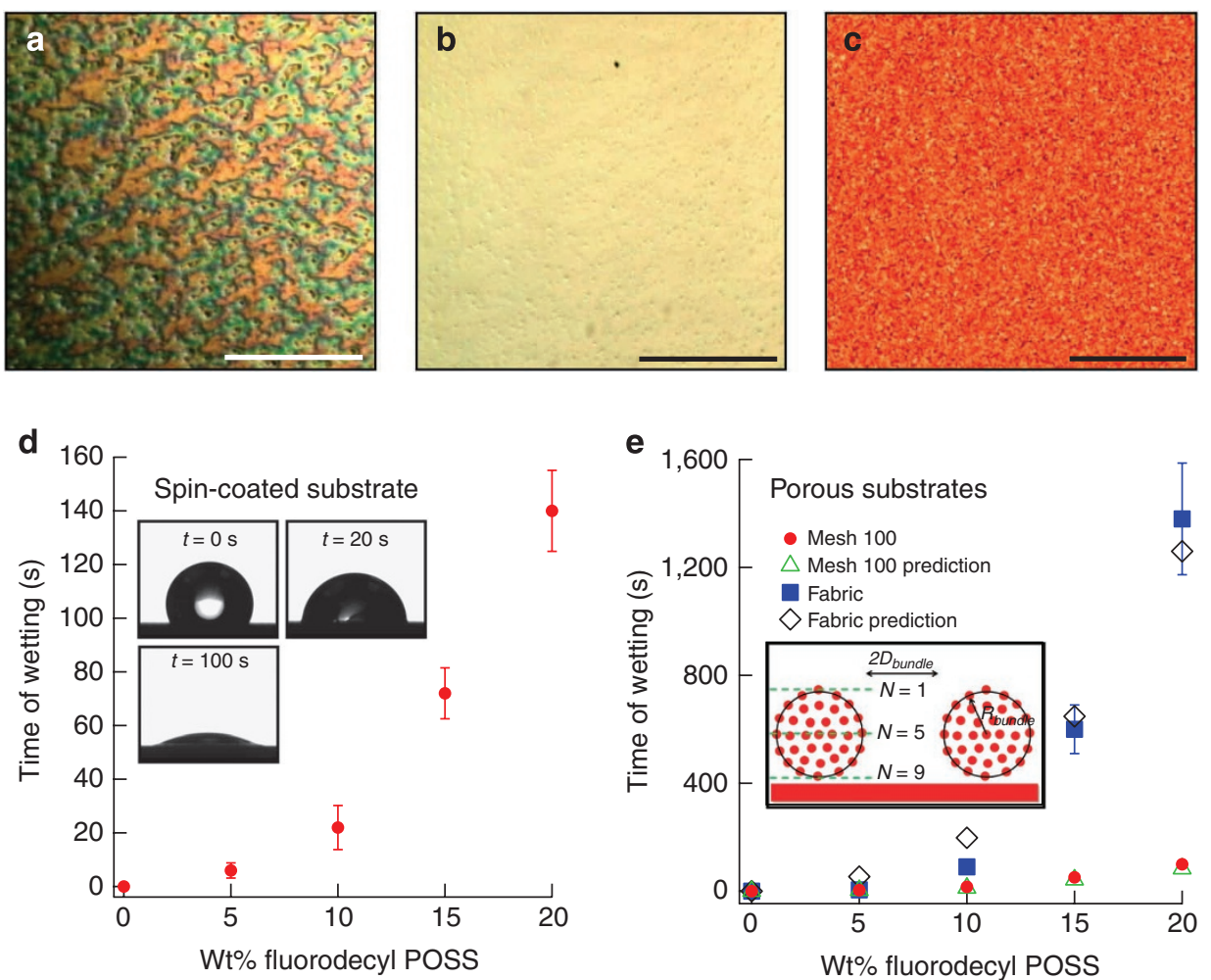

Figure 2 | Surface reconfiguration and ToW. (a,b) Optical microscopy images of a surface coated with a 20 wt $\%$ fluorodecyl POSS + $x$-PEGDA blend in air (a) and under water (b). Scale bars, $300 \mu \mathrm{m}$. (c) In situ, underwater AFM phase image of a surface coated with a 20 wt $\%$ fluorodecyl POSS + x-PEGDA. The phase angle range is $0^{\circ}-112^{\circ}$. Scale bar, $2 \mu \mathrm{m}$. (d,e) ToW of water for spin-coated (d) and porous (e) substrates. Error bars, s.d.; $n=5$. Insets in $\mathbf{d}$ show the time-dependent decrease in contact angle for a water droplet. Inset in $\mathbf{e}$ is a schematic illustrating the two scales of texture (bundles and individual fibres) for the fabric. The ToW predictions for mesh 100 and fabric membranes closely match experimental measurements, as shown in e.

aggregates. However, under water, fluorodecyl POSS aggregates disappear to reveal a smoother surface that is indicative of surface reconfiguration (Supplementary Movie 1). PEGDA chains reconfigure to increase their interfacial area with water and facilitate enthalpic gains through hydrogen bonding. Surface reconfiguration is further confirmed by the absence of large crystalline domains in the in situ, underwater AFM phase image (Fig. 2c). We conducted multiple water wetting-drying cycles and found that this surface reconfiguration is reversible (see Supplementary Fig. S3 and Supplementary Discussion). Surface energy analysis of the wet surface suggests that it is equivalent to an $\mathrm{x}$-PEGDA blend with $\sim 0.4-1.5$ wt\% fluorodecyl POSS (see Supplementary Discussion). 

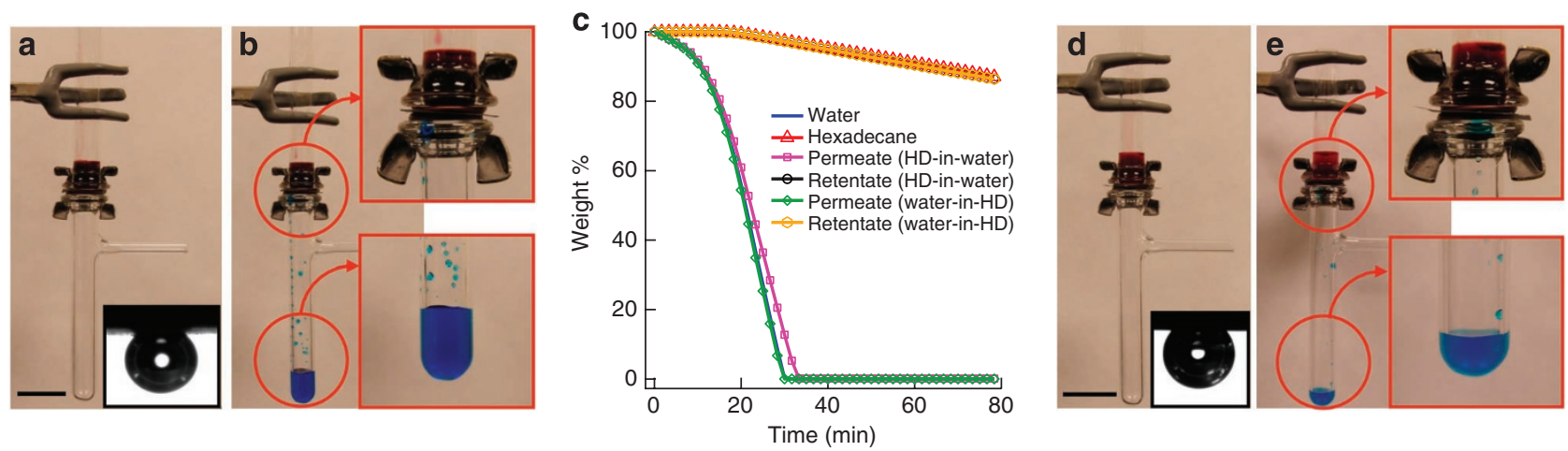

Figure 3 | Batch separation of oil-in-water and water-in-oil emulsions. (a) Separation apparatus with a 50:50 v:v hexadecane-in-water emulsion above the membrane. Inset, hexadecane droplet on a surface spin-coated with a $20 \mathrm{wt} \%$ fluorodecyl POSS + x-PEGDA blend, submerged in water containing dissolved SDS $\left(1 \mathrm{mg} \mathrm{ml}^{-1}\right)$. (b) Water-rich permeate passes through the membrane whereas hexadecane-rich retentate is retained. (c) TGA data for the permeates and the retentates. HD, hexadecane. (d) Apparatus with a 30:70 v:v water-in-hexadecane emulsion above the membrane. Inset, hexadecane droplet on a surface spin coated with a $20 \mathrm{wt} \%$ fluorodecyl POSS $+x$-PEGDA blend, submerged in water containing dissolved PS80 $\left(1 \mathrm{mg} \mathrm{ml}^{-1}\right)$.

(e) Water-rich permeate passes through the membrane whereas hexadecane-rich retentate is retained. Water is dyed blue and hexadecane is dyed red. Scale bars, $2 \mathrm{~cm}$.

Addition of fluorodecyl POSS causes a systematic increase in the time required for surface reconfiguration, as is evident from the increased time of wetting (ToW) for water on spin-coated fluorodecyl POSS $+\mathrm{x}$-PEGDA surfaces (Fig. 2d). This is likely due to a reduction in the initial interfacial area between PEGDA chains and the contacting water droplet with increasing fluorodecyl POSS concentration. We define ToW as the time required for the water contact angle on a surface to decrease from its initial value to $0^{\circ}$. We also measured ToW for water on the porous mesh and fabric membranes (Fig. 2e). On these surfaces, we define ToW as the time required for the water droplet to imbibe into the membrane. Membrane imbibition is not instantaneous for surfaces with reconfigurable chemistry. Rather, the water-air interface progressively penetrates into the surface texture and water permeates through the membrane once the robustness factor $A^{*}$ water $\leq 1$. (If the liquid does not permeate through the membrane pores, the solid-liquidair composite interface equilibrates at a location on the membrane where the local texture angle $(\psi)$ is equal to the Young's contact angle, $\theta$.) From equation (1), for mesh $100, A^{*}$ water $=1$ when $\theta_{\text {water }}=18^{\circ}$. Our ToW measurements on the dip-coated meshes match closely with the time required for $\theta_{\text {wateradv }}$ to decrease from its initial value to $18^{\circ}$ (Fig. 2e).

The ToW for water on the dip-coated fabrics was found to be considerably higher than ToW on the meshes. This is because water has to progressively wet multiple fibres during imbibition. The fabrics used in this work have interwoven bundles of fibres (Fig. 1b, inset). Each bundle contains several layers of smaller individual fibres that offer an additional length scale for air entrapment (Fig. 2e, inset). From equation (1), for water on an individual fibre $\left(R_{\text {fibre }}=5 \mu \mathrm{m}\right.$, $\left.D_{\text {fibre }}=20 \mu \mathrm{m}\right), A^{*}$ water $=1$ when $\theta_{\text {water }}=7^{\circ}$. Thus, the ToW for water on each layer of the fibres should be equal to the time taken for $\theta_{\text {water,adv }}$ to reach $7^{\circ}$, which is approximately equal to the ToW for water on spin-coated substrates. Assuming $N$ layers of individual fibres, the ToW for water on the fabric surface should be $N$ times the ToW for water on the spin-coated surface. Fitting the experimental data with this $N$ layer model yields a best fit for $N=9$, which seems to be a reasonable estimate, based on Fig. 1b, inset.

Capillary force-based separation. Very few reports on membrane separation $25,32,33$ and microfluidics ${ }^{34,35}$ have used the difference in capillary forces acting on the two phases as the primary mechanism to separate emulsions or dispersions. We call this methodology capillary force-based separation (CFS). In CFS, the wetting phase permeates through the membrane, whereas the non-wetting phase is retained. From equation (1), the breakthrough pressure required to force the non-wetting phase through a membrane already saturated by the wetting phase is

$$
P_{\text {breakthrough }}=\frac{2 R \gamma_{12}}{D^{2}} \frac{1-\cos \left(\theta^{\prime}\right)}{1+2(R / D) \sin \left(\theta^{\prime}\right)} .
$$

Here $\gamma_{12}$ is the interfacial tension between the wetting phase and the non-wetting phase, and $\theta$ is the contact angle of the non-wetting phase on the solid surface, both of which are completely immersed in the wetting phase. When pressure $P_{\text {applied }}<P_{\text {breakthrough }}$ is applied, only the wetting phase permeates through the membrane. We use CFS in this work because it combines both demulsification and separation into a single-unit operation, it provides a very high-quality permeate and it is inherently self-repairing ${ }^{34}$. For a CFS-based system to work effectively, it is necessary that the wetting phase contact the membrane. There are several techniques to achieve this goal: gravity-driven (if the wetting phase has a higher density than the non-wetting phase), electrostatic (if the wetting phase is a polar liquid) ${ }^{36}$, forced convection ${ }^{3,6,7}$, etc. In this work, we demonstrate a proof-of-concept prototype that solely utilizes gravity to engender separation of various oil-water mixtures.

Separation of oil-in-water emulsions. Figure 3a,b shows solely gravity-driven CFS of a hexadecane-in-water emulsion (50 vol\% hexadecane; Methods) stabilized using SDS (hydrophilic-lipophilic balance, HLB $=40$ ). The hexadecane droplet size distribution (see Supplementary Fig. S4 and Supplementary Discussion) indicates that the greatest number fraction of droplet diameters is in the range of $10-20 \mu \mathrm{m}$. The separation apparatus consists of a mesh $400(2 D=37.5 \mu \mathrm{m})$, dip-coated with a $20 \mathrm{wt} \%$ fluorodecyl POSS + $\mathrm{x}$-PEGDA blend and sandwiched between two vertical glass tubes. We used the superhydrophilic and oleophobic meshes here as they are available in a range of different pore sizes, allowing us to systematically vary the membrane porosity. Our superhydrophilic and superoleophobic fabrics show a similar performance. The emulsion is added to the upper tube (Fig. 3a). Once water in the emulsion contacts the membrane, the surface starts to reconfigure. Within minutes, the water-rich permeate passes through the membrane while the hexadecane-rich retentate is retained above the membrane (Fig. 3b). Membrane oleophobicity under water is critical for the separation of hexadecane-in-water emulsions (Fig. 3a, inset). Optical image analysis indicates that the membrane removes virtually all hexadecane droplets exceeding $40 \mu \mathrm{m}$ in diameter (see Supplementary Fig. S5 

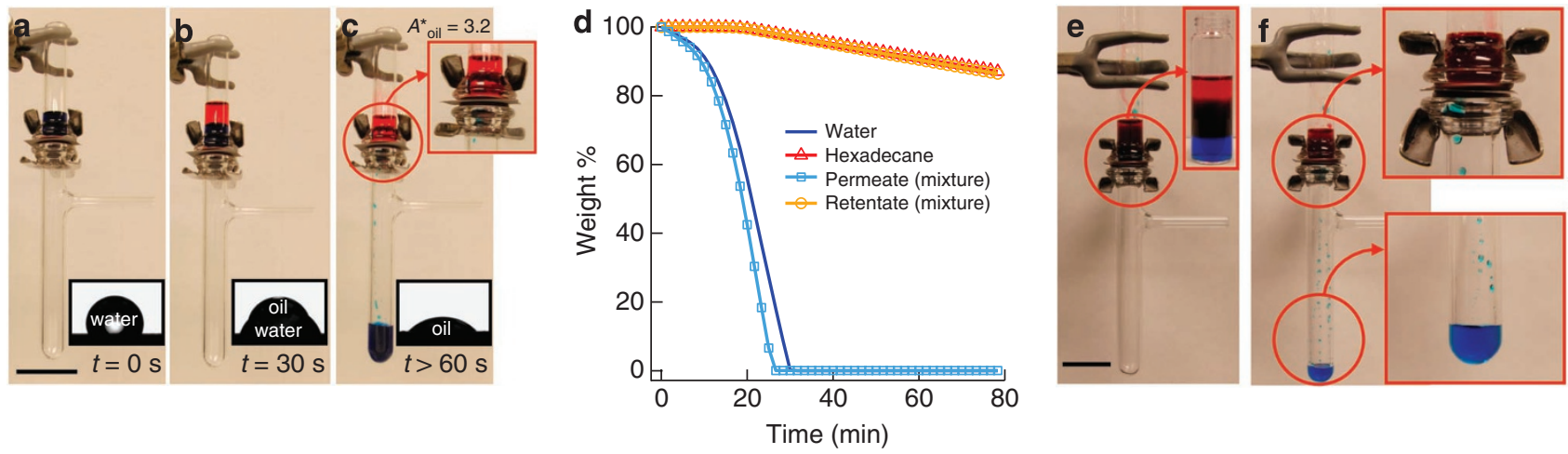

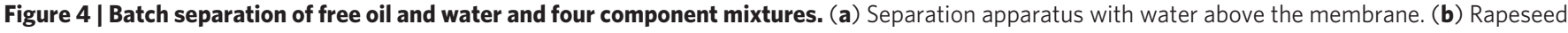
oil is added above water. (c) Water permeates through the membrane whereas rapeseed oil is retained. Insets, water droplet on a surface spin-coated with a 20 wt\% fluorodecyl POSS + x-PEGDA blend, rapeseed oil droplet on top of the water droplet, rapeseed oil droplet on the reconfigured surface. (d) TGA data for the permeate and the retentate. HD, hexadecane. (e) Apparatus with the four-component mixture above the membrane. Inset, larger quantity of feed in a glass vial, depicting the presence of different phases. (f) Water-rich permeate passes through the membrane whereas hexadecanerich retentate is retained. Water is dyed blue, hexadecane and rapeseed oil are dyed red. Scale bars, $2 \mathrm{~cm}$.

and Supplementary Discussion). Thermogravimetric analyses (TGA; Fig. 3c), transmittance and density measurements (see Supplementary Fig. S6 and Supplementary Discussion) indicate that the permeate contains $\sim 0.1 \mathrm{wt} \%$ hexadecane, whereas the retentate contains $\sim 0.1 \mathrm{wt} \%$ water. Additional experiments showed that we can similarly separate, with $>99 \%$ efficiency, hexadecane-in-water emulsions containing 10 vol\% and 30 vol\% hexadecane. We also conducted experiments with hexadecane-in-water emulsions containing salt (sodium chloride). As with the non-saline emulsions, we could separate saline emulsions with $>99 \%$ efficiency.

Separation of water-in-oil emulsions. Figure 3d,e shows the solely gravity-driven CFS of a water-in-oil emulsion (30 vol\% water; Methods) stabilized using Polysorbate80 (PS80; HLB =15). The apparatus is the same as that used for the separation of oil-in-water emulsions. The emulsion is added to the upper tube (Fig. 3d). Once water droplets within the emulsion contact the membrane, the surface starts to reconfigure. Before the breakthrough of the water-rich permeate, hexadecane is retained above the membrane because of membrane oleophobicity in air. After surface reconfiguration, the water-rich permeate passes through the membrane while the hexadecane-rich retentate is retained above the membrane (Fig. 3e). During the permeation of the water-rich permeate, the hexadecanerich retentate is retained above the membrane because of membrane oleophobicity under water. Membrane oleophobicity, both in air and under water, is critical for separating water-in-hexadecane emulsions. TGA (Fig. 3c), transmittance and density measurements (see Supplementary Fig. S6 and Supplementary Discussion) indicate that the permeate contains $\sim 0.1 \mathrm{wt} \%$ hexadecane, whereas the retentate contains $\sim 0.1 \mathrm{wt} \%$ water. Additional experiments showed that we can similarly separate, with $>99 \%$ efficiency, water-in-hexadecane emulsions containing 10 vol\% and 20 vol\% water. Further, we can also similarly separate span $80(\mathrm{HLB}=4.3)$ stabilized water-in-hexadecane emulsions containing 10, 20 and 30 vol\% water, with $>99 \%$ efficiency. Our analysis also indicates that after separation, the surfactant fractionates into both the water-rich and the hexadecanerich phases, depending upon its relative solubility in each phase (see Supplementary Fig. S7 and Supplementary Discussion).

Separation of free oil and water. Figure $4 \mathrm{a}-\mathrm{c}$ show the solely gravity-driven CFS of free rapeseed oil and water using a mesh 100 $(2 D=138 \mu \mathrm{m})$ coated with a $20 \mathrm{wt} \%$ fluorodecyl POSS + $\mathrm{x}-\mathrm{PEGDA}$ blend. Water is added to the upper tube (Fig. 4a) immediately followed by rapeseed oil (Fig. 4b). The corresponding insets in
Fig. 4a,b show a drop of water placed on a spin-coated surface of 20 wt $\%$ fluorodecyl POSS + x-PEGDA, and a drop of rapeseed oil immediately placed on top of the drop of water, respectively. Upon surface reconfiguration, water permeates through the membrane, while rapeseed oil is retained above the membrane (Fig. 4c). On a spin-coated $20 \mathrm{wt} \%$ fluorodecyl POSS + $\mathrm{x}$-PEGDA surface, previously wet by water, a drop of rapeseed oil displays a contact angle of $\theta_{\text {oil,adv }}=45^{\circ}$ (Fig. 4c, inset (ii)). Thus, for rapeseed oil on the membrane, the robustness factor $A^{*}$ oil $=3.2$. Consequently, rapeseed oil is retained above the membrane. A video illustrating the nearly complete separation of free oil and water is provided as Supplementary Movie 2. As illustrated in the video, water permeates through the membrane at $A^{*}$ water $=1.25$. The experimentally measured flux of water through the membrane (mesh $100 ; 2 D=138 \mu \mathrm{m}$ ), $Q_{\text {water }} \approx 43,2001 \mathrm{~m}^{-2} \mathrm{~h}^{-1}$. This is significantly lower than the flux of the water $(\mu \sim 1 \mathrm{mPas})$, $Q_{\text {water }}=509,0001 \mathrm{~m}^{-2} \mathrm{~h}^{-1}$, predicted using the Hagen-Poiseuille relation $^{37}$. This is because the number of pores through which water is flowing at any given time (so-called 'active pores') in CFS can be significantly lower $(\sim 1-10 \%)$ than the actual number of pores ${ }^{35}$. Comparing the measured and the predicted fluxes, we estimate that $\sim 8.5 \%$ of the total pores are active during the separation of free oil and water.

Separation of four-component mixtures. Figure $4 \mathrm{e}, \mathrm{f}$ show the separation of a mixture containing four components: water, hexadecane, a 30:70 v:v water-in-hexadecane emulsion and a 50:50 v:v hexadecane-in-water emulsion. Again, mesh 400 dip coated with a $20 \mathrm{wt} \%$ fluorodecyl POSS + $\mathrm{x}$-PEGDA blend separated this mixture into highly pure constituents, that is, a permeate containing $\sim 0.1 \mathrm{wt} \%$ hexadecane and a retentate containing $\sim 0.1 \mathrm{wt} \%$ water, as confirmed by TGA (Fig. 4d). To our knowledge, this is the first ever report of solely gravity-driven separation of surfactant-stabilized emulsions and their mixtures into highly pure constituents. Furthermore, the dip-coating-based membrane fabrication process is easy to scale up, and we have developed an apparatus to separate several litres of oil-water mixtures (Supplementary Movie 3). As illustrated in the video, separation occurs even if the non-wetting phase (oil) contacts the dry membrane before the wetting phase.

Breakthrough height. For the separation apparatus shown in Figs 3 and 4 the maximum height of the liquid column before the oil phase permeates through the membrane ( $h_{\text {breakthrough }}$ ) can be obtained using equation (1) when the membrane is in air or equation (2) when the membrane is submerged under water. Note that 
a

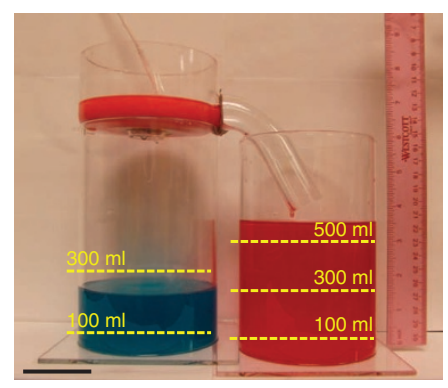

b

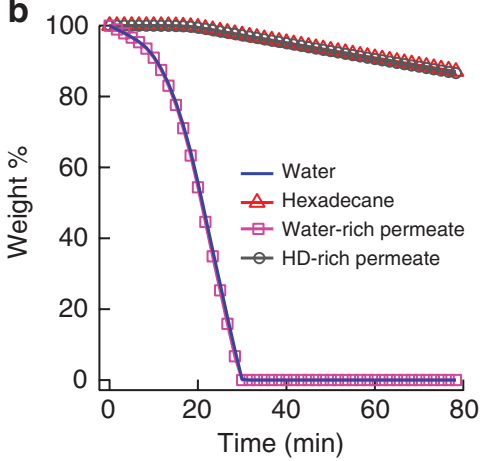

C

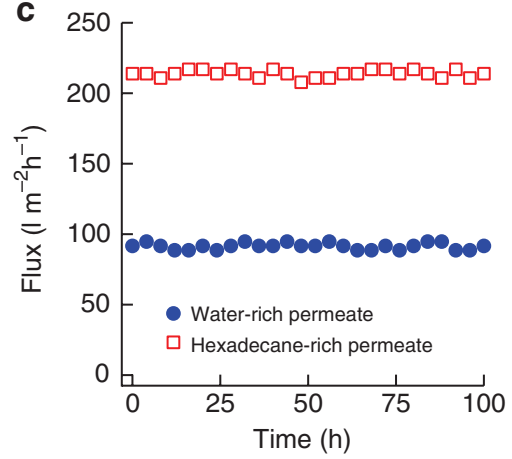

Figure 5 | Continuous separation of water-in-oil emulsions. (a) A scaled-up apparatus used for the continuous separation of 30:70 v:v water-inhexadecane emulsions stabilized by polysorbate 80 . The superhydrophilic and oleophobic mesh 400 was prepared by dip coating with a 20 wt\% fluorodecyl POSS + x-PEGDA blend, whereas the hydrophobic and oleophilic mesh 400 was prepared by dip coating with Desmopan 9370 $\left(\gamma_{\mathrm{sv}}=35.6 \mathrm{mN} \mathrm{m}^{-1}\right.$; see Supplementary Table S1 and Supplementary Discussion). During continuous separation, water-rich permeate continuously passes through the superhydrophilic and oleophobic membrane, whereas hexadecane-rich permeate continuously passes through the hydrophobic and oleophilic membrane. Water is dyed blue and hexadecane is dyed red. Scale bar, $5 \mathrm{~cm}$. (b) TGA data for both the permeates. (c) Measured fluxes for both the permeates as a function of time.

$P_{\text {breakthrough }}=\rho g h_{\text {breakthrough. }}$ For free oil and water separation, $\theta_{\text {oil,adv }}=45^{\circ}, \gamma_{\mathrm{lv}}=35.7 \mathrm{mN} \mathrm{m}^{-1}$ and $h_{\text {breakthrough }}$ is predicted to be $1.3 \mathrm{~cm}\left(P_{\text {breakthrough }}=117 \mathrm{~Pa}\right)$ using equation (1). For the SDSstabilized 50:50 v:v hexadecane-in-water emulsion, $\theta_{\text {oil adv }}=120^{\circ}$ (Fig. 3a, inset), $\gamma_{12}=4.0 \mathrm{mN} \mathrm{m}^{-1}$ and $h_{\text {breakthrough }}$ is predicted to be $2.3 \mathrm{~cm}\left(P_{\text {breakthrough }}=198 \mathrm{~Pa}\right)$ using equation (2). For waterin-oil emulsions, $h_{\text {breakthrough }}$ should be predicted using equation (1) before the breakthrough of the water-rich permeate and using equation (2) during the permeation of the water-rich permeate. The lower value of the two predicted breakthrough heights limits the operating height. For the PS80-stabilized 30:70 v:v water-inhexadecane emulsion, before the breakthrough of the water-rich permeate, $\theta_{\mathrm{oil}, \mathrm{adv}}=70^{\circ}, \gamma_{\mathrm{v}}=24.9 \mathrm{mN} \mathrm{m}^{-1}$ and $h_{\text {breakthrough }}$ is predicted to be $6.3 \mathrm{~cm}\left(P_{\text {breakthrough }}=519 \mathrm{~Pa}\right)$ using equation (1). For the same emulsion, during the permeation of the water-rich permeate, $\theta_{\text {oil }, \text { adv }}=125^{\circ}$ (Fig. $3 \mathrm{~d}$, inset), $\gamma_{12}=3.7 \mathrm{mN} \mathrm{m}^{-1}$ and $h_{\text {breakthrough }}$ is predicted to be $2.4 \mathrm{~cm}\left(P_{\text {breakthrough }}=198 \mathrm{~Pa}\right)$. Consequently, the operating height during the water-in-hexadecane emulsion separation is limited by $h_{\text {breakthrough }}$ during the permeation of the water-rich permeate. Indeed, these predicted values of $h_{\text {breakthrough }}$ closely match experimentally measured values of $1.3 \mathrm{~cm}, 2 \mathrm{~cm}$ and $2.2 \mathrm{~cm}$ for the free oil and water, hexadecane-in-water emulsion and water-in-hexadecane emulsion separation, respectively. In the above analysis, we estimated the surface tension of hexadecane and the hexadecane-water interfacial tension, in the presence of surfactants, using the capillary-rise method ${ }^{37}$ and the Fowkes ${ }^{38}$ relationship (see Supplementary Discussion). To ensure CFS, we used an operating height $h<h_{\text {breakthrough }}$ in all our separation operations.

Continuous separation of oil-water emulsions. In the separation apparatus design discussed above, oil accumulates above the membrane over time and will eventually break through once the operating height $>h_{\text {breakthrough. }}$ Therefore, we developed a continuous oil-water separation apparatus (Fig. 5a), with two CFS-based operations in parallel, using a superhydrophilic and oleophobic membrane at the bottom and a hydrophobic and oleophilic membrane on the side wall. Using this apparatus, we achieved continuous, solely gravity-driven CFS of oil-water emulsions (Supplementary Movie 4). TGA (Fig. 5b) indicates that the water-rich permeate contains $\sim 0.1 \mathrm{wt} \%$ hexadecane and that the hexadecane-rich permeate contains $\sim 0.1 \mathrm{wt} \%$ water, which is the limit of detection using TGA. Karl Fischer analysis indicates that the hexadecane-rich permeate contains $\sim 25 \pm 8$ p.p.m. water, which is comparable to the solubility of water in hexadecane $\left(\sim 30\right.$ p.p.m. at $25^{\circ} \mathrm{C}$ ) (see Supplementary
Discussion). Analysis of the hexadecane-rich permeate also indicates that at least $99.8 \%$ of water droplets with diameter $<20 \mu \mathrm{m}$ are removed during separation (see Supplementary Fig. S8 and Supplementary Discussion). Thus, it is clear that the membrane allows for the removal of dispersed-phase droplets that are considerably smaller than the membrane pore size $(2 D=37.5 \mu \mathrm{m})$. To our knowledge, this is the first demonstration of continuous, solely gravitydriven CFS of surfactant-stabilized emulsions into highly pure constituents.

Fluxes of water-rich and hexadecane-rich permeates through the membranes were measured to be 90 and $210 \mathrm{~lm}^{-2} \mathrm{~h}^{-1}$, respectively. These values are comparable to those reported in previous work on membrane separation under externally applied pressures $3,4,6,7,39,40$. Furthermore, in intermittent stop-and-go operation, the fluxes did not decrease over a period of $100 \mathrm{~h}$ (Fig. 5c and Supplementary Table S2), indicating that the membranes are highly resistant to fouling by oil. Membrane wettability, and the considerably larger pore sizes of the membranes used here, compared with those used traditionally $3,5,7,8$, are expected to be two major contributing factors towards the observed resistance to fouling.

\section{Discussion}

The flux of the water-rich permeate during continuous separation of water-in-oil emulsions is limited by the sedimentation velocity of the water droplets. On the basis of this understanding, we predicted the flux to be $Q_{\text {water }} \approx 831 \mathrm{~m}^{-2} \mathrm{~h}^{-1}$ (see Supplementary Discussion), which closely matches experimental results. However, as the pore size decreases, according to the Hagen-Poiseuille relation, the allowable flux of the water-rich permeate through membrane decreases. We calculated that the flux predicted by the Hagen-Poiseuille relation equals the flux predicted by the sedimentation velocity of the water droplets when the membrane pore diameter is $\sim 4.5 \mu \mathrm{m}$. Thus, for all pore diameters $2 D \gg 4.5 \mu \mathrm{m}$, the flux of water-rich permeate is only limited by the sedimentation velocity and is independent of the pore diameter. Indeed, experimentally we obtained almost the same flux for water using both mesh $400(2 D=37.5 \mu \mathrm{m})$ and mesh $500(2 D=30.5 \mu \mathrm{m})$ during continuous separation. A membrane with a smaller pore diameter, such as mesh 500 , has a higher value for $P_{\text {breakthrough }}$ and is therefore more resistant to pressure perturbations.

In conclusion, we have developed novel membranes with hygroresponsive surfaces, which are both superhydrophilic and superoleophobic. These membranes are oleophobic both in air and when submerged under water. Consequently, CFS-based unit operations 
using these membranes can separate a range of different oil-water mixtures, with $>99 \%$ efficiency. We have also engineered an apparatus that uses two CFS-based operations in parallel to achieve continuous, solely gravity-driven separation of oil-water emulsions, with a separation efficiency $\geq 99.9 \%$. We anticipate that our separation methodology will have numerous applications, including the clean-up of oil spills, wastewater treatment, fuel purification and the separation of commercially relevant emulsions.

\section{Methods}

Materials. PEGDA with a number-average molecular mass of $M_{\mathrm{n}} \approx 700 \mathrm{Da}$ and its cross-linker 2-hydroxy-2-methyl propiophenone (Darocur1173) were obtained from Sigma Aldrich. Tecnoflon BR9151 fluoroelastomer was obtained from Solvay Solexis. Desmopan 9370 polyurethane was obtained from Bayer Material Science. $1 \mathrm{H}, 1 \mathrm{H}, 2 \mathrm{H}, 2 \mathrm{H}$-heptadecafluorodecyl polyhedral oligomeric silsequioxane (fluorodecyl POSS) was synthesized as described elsewhere ${ }^{15}$. Asahiklin AK-225 solvent was obtained from Structure Probe, Inc. Rapeseed oil, hexadecane, tetrahydrofuran, methylene blue (blue dye), oil red-o (red dye), sodium dodecyl sulphate, polysorbate 80 and span 80 were obtained from Fisher Scientific. Stainless steel meshes of mesh size $100\left(R=56.5 \mu \mathrm{m}, 2 D=138 \mu \mathrm{m}, D^{*}=2.2\right), 400(R=12.5 \mu \mathrm{m}$, $\left.2 D=37.5 \mu \mathrm{m}, D^{*}=2.5\right), 500\left(R=10.2 \mu \mathrm{m}, 2 D=30.5 \mu \mathrm{m}, D^{*}=2.5\right)$ were obtained from McMaster Carr. The mesh number refers to the number of openings per inch. The fabric Anticon $100\left(R_{\text {bundle }}=150 \mu \mathrm{m}, 2 D_{\text {bundle }}=300 \mu \mathrm{m}, R_{\text {fibre }}=5 \mu \mathrm{m}\right.$, $2 D_{\text {fibre }}=20 \mu \mathrm{m} ; D^{*}=6$ as described elsewhere ${ }^{28}$ ) was obtained from VWR. Silicon wafers were obtained from the clean room at the University of Michigan.

Substrate preparation. Solutions $\left(100 \mathrm{mg} \mathrm{ml}^{-1}\right)$ of PEGDA, Darocur 1173 and fluorodecyl POSS were prepared in Asahiklin AK-225. The PEGDA:Darcour1173 ratio was 95:5 w:w. The fluorodecyl POSS concentrations studied were 0, 0.5, 1 , $2,5,10,15$ and $20 \mathrm{wt} \%$. Solutions $\left(10 \mathrm{mg} \mathrm{ml}^{-1}\right)$ of Desmopan were prepared in tetrahydrofuran. Small pieces of mesh and fabric $(2 \times 2 \mathrm{~cm})$ were dip-coated in the desired solution for $10 \mathrm{~min}$ and dried with nitrogen gas at room temperature $\left(\sim 22^{\circ} \mathrm{C}\right)$ for $5 \mathrm{~min}$. The non-textured substrates (silicon wafers, $2 \times 2 \mathrm{~cm}$ ) were spincoated using Speciality Coating Systems Spincoater G3P-8 for $30 \mathrm{~s}$ at 250-2,000 r.p.m. (0.7-44.7 g). After dip coating or spin coating, the PEGDA-containing surfaces were cross-linked for 5 min using a UVP XX-40S ultra violet bench lamp (wavelength, $254 \mathrm{~nm}$ ). The thickness of the dip-coated layer varied between $100 \mathrm{~nm}$ and $1 \mu \mathrm{m}$.

Oil-water emulsions. Hexadecane-in-water emulsions $(10: 90,30: 70$ and $50: 50 \mathrm{v}$ v) were prepared by mixing water and hexadecane using a stir bar (at 700-1,200 r.p.m., or 3.4-10.1 $\mathrm{g}$ ) with $0.1-0.5 \mathrm{mg}$ of SDS per $\mathrm{ml}$ of emulsion, whereas 10:90, 20:80 and 30:70 v:v water-in-hexadecane emulsions were prepared with 0.1-0.3 mg of PS 80 per $\mathrm{ml}$ of emulsion and $0.1-0.3 \mathrm{mg}$ of span 80 per $\mathrm{ml}$ of emulsion. Over time, a small degree of demulsification was observed for some emulsions. We determined whether an emulsion is hexadecane-in-water or water-in-hexadecane by measuring the electrical resistance with a multimetre. A KDScientific KDS-200 syringe pump was used to deliver the feed emulsions during continuous separation.

Contact angle measurement. All measurements of contact angle (in air and under water) were conducted using a Ramé-Hart 200-F1 goniometer. All contact angles reported in this work were measured by advancing or receding a small volume of liquid ( $\sim 2 \mu \mathrm{l})$ onto the surface using a 2 -ml micrometre syringe (Gilmont). At least three measurements were performed on each substrate. The typical error in measurements was $\pm 2^{\circ}$.

Microscopy. Tapping-mode atomic force microscopy was conducted in air and under water using a Veeco Innova Instrument. Veeco TESPA tips were used for imaging in air, and Veeco SNL-10C tips were used for imaging under water. The thickness of the spin-coated films was determined using an AFM line scan across a scratched location. To ensure conformal coating, scanning electron microscopy of the dip-coated surfaces was conducted using a Hitachi SU8000 at $5 \mathrm{kV}$. Optical microscopy of the dry and wet spin-coated surfaces was conducted using an Olympus BH-2 optical microscope.

Separation efficiency and droplet size distribution. The water content in both the hexadecane-rich phase and the water-rich phase after separation was measured using a Perkin Elmer Pyris 1 TGA. Approximately $50 \mathrm{mg}$ of the sample was heated from room temperature to $105^{\circ} \mathrm{C}$ at a rate of $5^{\circ} \mathrm{C}$ per min, and the temperature was held constant at $105^{\circ} \mathrm{C}$ for $60 \mathrm{~min}$. Note that the boiling point of hexadecane is $287^{\circ} \mathrm{C}$. The loss in weight of water was used to estimate the purity of the water-rich phase. The loss in weight of the hexadecane-rich phase was compared with the loss in weight of the as-obtained hexadecane to estimate the purity of the hexadecanerich phase. The water content in the hexadecane-rich phase was also determined by injecting samples ranging in volume from $10 \mu \mathrm{l}$ to $0.6 \mathrm{ml}$ into an EM Science AquaStar C3000 Titrator for coulometric Karl Fischer titration analysis (ASTM D6304). The transmittance of the feed emulsions and permeates was measured using a Cary 50 Bio ultra violet-Visible spectrophotometer. The size distribution of the dispersed phase with droplet sizes $<1 \mu \mathrm{m}$ was determined by dynamic light scattering using a Malvern Zetasizer Nano ZS instrument.

\section{References}

1. Kintisch, E. An audacious decision in crisis gets cautious praise. Science 329, 735-736 (2010)

2. Cheryan, M. \& Rajagopalan, N. Membrane processing of oily streams. Wastewater treatment and waste reduction. J. Membrane Sci. 151, 13-28 (1998).

3. Hlavacek, M. Break-up of oil-in-water emulsions induced by permeation through a microfiltration membrane. J. Membrane Sci. 102, 1-7 (1995).

4. Sun, D. Z., Duan, X. D., Li, W. X. \& Zhou, D. Demulsification of water-in-oil emulsion by using porous glass membrane. J. Membrane Sci. 146, 65-72 (1998).

5. Hoffmann, S. \& Nitsch, W. Membrane coalescence for phase separation of oil-in-water emulsions stabilized by surfactants and dispersed into smallest droplets. Chem. Eng. Technol. 24, 22-27 (2001).

6. Maartens, A., Jacobs, E. P. \& Swart, P. UF of pulp and paper effluent: membrane fouling-prevention and cleaning. J. Membrane Sci. 209, 81-92 (2002).

7. Hu, B. \& Scott, K. Influence of membrane material and corrugation and process conditions on emulsion microfiltration. J. Membrane Sci. 294, 30-39 (2007).

8. Kukizaki, M. \& Goto, M. Demulsification of water-in-oil emulsions by permeation through Shirasu-porous-glass (SPG) membranes. J. Membrane Sci. 322, 196-203 (2008).

9. Feng, L. et al. A super-hydrophobic and super-oleophilic coating mesh film for the separation of oil and Water13. Angew. Chem. Int. Ed. 43, 2012-2014 (2004).

10. Tian, D., Zhang, X., Wang, X., Zhai, J. \& Jiang, L. Micro/nanoscale hierarchical structured $\mathrm{ZnO}$ mesh film for separation of water and oil. Phys. Chem. Chem. Phys. 13, 14606-14610 (2011)

11. Yuan, J. et al. Superwetting nanowire membranes for selective absorption. Nat. Nanotech. 3, 332-336 (2008).

12. Tadros, T., Izquierdo, R., Esquena, J. \& Solans, C. Formation and stability of nano-emulsions. Adv. Colloid Interface Sci. 108, 303-318 (2004).

13. Meunier, J. et al. Physics of Amphiphilic Layers, Springer, Les Houches, 1987.

14. Yang, J et al. Superhydrophilic-superoleophobic coatings. J. Mater. Chem. 22, 2834-2837 (2012).

15. Tuteja, A. et al. Designing superoleophobic surfaces. Science 318, 1618-1622 (2007).

16. Jung, Y. C. \& Bhushan, B. Wetting behavior of water and oil droplets in three phase interfaces for hydrophobicity/philicity and oleophobicity/philicity. Langmuir 25, 14165-14173 (2009).

17. Lin, L. et al. Bio-inspired hierarchical macromolecule-nanoclay hydrogels for robust underwater superoleophobicity. Adv. Mater. 22, 4826-4830 (2010).

18. Ahuja, A. et al. Nanonails: a simple geometrical approach to electrically tunable superlyophobic surfaces. Langmuir 24, 9-14 (2008).

19. Tuteja, A., Choi, W., Mabry, J. M., McKinley, G. H. \& Cohen, R. E. Robust omniphobic surfaces. P. Natl Acad. Sci. USA 105, 18200-18205 (2008).

20. Young, T. An essay on the cohesion of fluids. Philos. T. R. Soc. Lond. 95, 65 (1805).

21. Vaidya, A. \& Chaudhury, M. K. Synthesis and surface properties of environmentally responsive segmented polyurethanes. J. Colloid Interface Sci. 249, 235-245 (2002).

22. Sawada, H., Ikematsu, Y., Kawase, T. \& Hayakawa, Y. Synthesis and surface properties of novel fluoroalkylated flip-flop-type silane coupling agents. Langmuir 12, 3529-3530 (1996).

23. Hutton, S. J., Crowther, J. M. \& Badyal, J. P. S. Complexation of fluorosurfactants to functionalized solid surfaces: smart behavior. Chem. Mater. 12, 2282-2286 (2000)

24. Howarter, J. A. \& Youngblood, J. P. Self-cleaning and anti-fog surfaces via stimuli-responsive polymer brushes. Adv. Mater. 19, 3838-3843 (2007)

25. Howarter, J. A. \& Youngblood, J. P. Amphiphile grafted membranes for the separation of oil-in-water dispersions. J. Colloid Interface Sci. 329, 127-132 (2009).

26. Arifuzzaman, S., Oezcam, A. E., Efimenko, K., Fischer, D. A. \& Genzer, J. Formation of surface-grafted polymeric amphiphilic coatings comprising ethylene glycol and fluorinated groups and their response to protein adsorption. Biointerphases 4, FA33-FA44 (2009).

27. Cao, L., Price, T. P., Weiss, M. \& Gao, D. Super water- and oil-repellent surfaces on intrinsically hydrophilic and oleophilic porous silicon films. Langmuir $\mathbf{2 4}$ 1640-1643 (2008).

28. Choi, W. et al. Fabrics with tunable oleophobicity. Adv. Mater. 21, 2190-2195 (2009).

29. Leng, B., Shao, Z., de With, G. \& Ming, W. Superoleophobic cotton textiles. Langmuir 25, 2456-2460 (2009).

30. Marmur, A. From hygrophilic to superhygrophobic: theoretical conditions for making high-contact-angle surfaces from low-contact-angle materials. Langmuir 24, 7573-7579 (2008).

31. Kwon, G. et al. On-demand separation of oil-water mixtures. Adv. Mater. 24 3666-3671 (2012). 
32. Tirmizi, N. P., Raghuraman, B. \& Wiencek, J. Demulsification of water/oil/ solid emulsions by hollow-fiber membranes. AIChE J. 42, 1263-1276 (1996).

33. Xue, Z. et al. A novel superhydrophilic and underwater superoleophobic hydrogel-coated mesh for oil/water separation. Adv. Mater. 23, 4270-4273 (2011).

34. Angelescu, D. E., Mercier, B., Siess, D. \& Schroeder, R. Microfluidic capillary separation and real-time spectroscopic analysis of specific components from multiphase mixtures. Anal. Chem. 82, 2412-2420 (2010).

35. Kralj, J. G., Sahoo, H. R. \& Jensen, K. F. Integrated continuous microfluidic liquid-liquid extraction. Lab Chip 7, 256-263 (2007).

36. Ichikawa, T., Itoh, K., Yamamoto, S. \& Sumita, M. Rapid demulsification of dense oil-in-water emulsion by low external electric field: I. Experimental evidence. Colloid Surface A 242, 21-26 (2004).

37. Batchelor, G. K. An Introduction in Fluid Dynamics (Cambridge University Press, Cambridge, 1970).

38. Fowkes, F. M. Attractive forces at interfaces. Ind. Eng. Chem. 56, 40-52 (1964).

39. Arnot, T. C., Field, R. W. \& Koltuniewicz, A. B. Cross-flow and dead-end microfiltration of oily-water emulsions - Part II. Mechanisms and modelling of flux decline. J. Membrane Sci. 169, 1-15 (2000).

40. Koltuniewicz, A. B., Field, R. W. \& Arnot, T. C. Cross-flow and dead-end microfiltration of oily-water emulsion .1. Experimental-study and analysis of flux decline. J. Membrane Sci. 102, 193-207 (1995).

\section{Acknowledgements}

We thank C. Y.-C. Lee and the Air Force Office of Scientific Research for financial support under grants FA9550-10-1-0523 and LRIR-12RZ03COR. We thank R. E. Cohen, G. H. McKinley, D. Lee, J. P. Youngblood and B. J. Love for comments. We also thank J. Kim, N. A. Kotov and M. J. Solomon for use of facilities. We thank B. Wight for help with Karl Fischer analysis.

\section{Author contributions}

A.K.K. and G.K. performed the experiments, analyzed data and wrote the manuscript. W.C. analyzed data and wrote the manuscript. J.M.M. performed experiments, analyzed data and wrote the manuscript. A.T. conceived the project, designed the experiments, analyzed data and wrote the manuscript.

\section{Additional information}

Supplementary Information accompanies this paper at http://www.nature.com/ naturecommunications

Competing financial interests: The authors declare no competing financial interests. Reprints and permission information is available online at http://npg.nature.com/ reprintsandpermissions/

How to cite this article: Kota, A. K. et al. Hygro-responsive membranes for effective oil-water separation. Nat. Commun. 3:1025 doi: 10.1038/2027 (2012). 